\title{
Prevention of postoperative atelectasis in the post- cardiac surgical patient with poor left ventricular function: a study of the efficacy of bi-level positive airway pressure
}

\begin{abstract}
Background and aims: To determine the efficacy of Bi-level positive airway pressure (BiPAP) in prevention of postoperative atelectasis in patients with Off Pump Coronary Artery Bypass Grafting (OPCAB) with low left ventricular ejection fraction $£ 35 \%$ and effect on various hemodynamic \& oxygenation parameter.

Subjects and methods: This Prospective, randomized, case-controlled, pilot study included forty patients, who underwent elective (OPCAB) and were randomized into two groups i.e. group-B (BiPAP) and group- $\mathrm{C}$ (Control). All patients received same regimen of medication. Group-B was kept on BiPAP immediately following extubation, while, group-C received conventional physiotherapy only. All hemodynamic and oxygenation parameter were recorded and chest radiographs were done to find out incidence of atelectasis. Patients were followed up to their discharge.

Results: In group B, cardiac output was reduced after application of BiPAP at $0 \& 12 \mathrm{hrs}$ but later on it normalized. There was no other significant effect on other hemodynamic parameters. As far as the oxygenation is concerned $\mathrm{PaO}_{2}$ remained high throughout first $48 \mathrm{hrs}$ and the difference in $\mathrm{PaO}_{2}$ was significant at $12 \mathrm{hrs}\left(\mathrm{PaO}_{2} \mathrm{mmHg}\right.$ - group B-146 \pm 37 , group $\mathrm{C}-121 \pm 18)(\mathrm{p}<0.05)$ and at $48 \mathrm{hrs}\left(\mathrm{PaO}_{2} \mathrm{mmHg}\right.$-group-B-146 \pm 41 , group-C- $\left.110 \pm 9\right)$ $(\mathrm{p}<0.05)$. Arterial blood oxygen saturation was better maintained in group-B. There was significant difference in the occurrence of atelectasis in group-B and group-C $(10 \% \mathrm{v} / \mathrm{s}$ $60 \%)(p<0.003)$. Although the effects on ICU stay, hospital stay and mortality was same.

Conclusion: In patients, undergoing elective cardiac surgery with low Ejection Fraction intensive use of BiPAP can be considered as effective means of avoiding the deleterious consequences of cardiac surgery on postoperative pulmonary complications originating form atelectasis.
\end{abstract}

Keywords: atelectasis, off pump coronary artery bypass grafting, bi-level positive, airway pressure, left ventricular ejection fraction
Volume 4 Issue I - 2017

\section{Mayank Vats, Yatin Mehta, Satish Kumar, Deepa Vats, Taha Yaseen, Shivinder Singh Poonam Khurana, Naresh Trehan \\ Escorts Heart Institute and Research Centre, India}

Correspondence: Mayank Vats, Escorts Heart Institute and Research Centre, Okhla Road, New Delhi-I 10 025, India, Emaildrmayankvats@gmail.com

Received: November 23, 2016 | Published: February 0I, 2017

\section{Introduction}

Cardiac surgery frequently results in post operative pulmonary restriction syndrome. This syndrome is multi-factorial including post operative pain, absorption atelectasis, effect of anesthetic/sedative drugs and phrenic nerve dysfunction. ${ }^{1}$ These all combined together lead to high incidence of postoperative pulmonary complications, which includes retention of tracheo-bronchial secretions, atelectasis and pneumonia. ${ }^{2}$ These complications produces secondary hypoxemia, prolonged ventilator use and ventilator associated pneumonia with subsequent increased Intensive care unit (ICU) and hospital stays as well as increased morbidity and mortality. ${ }^{3}$ Conventional chest physiotherapy, incentive spirometry (IS) and intermittent positive pressure breathing (IPBB), used in an attempt to improve post operative pulmonary functions, may have a beneficial effect in post operative pulmonary impairement., ${ }^{4,5}$ Continuous positive airway pressure (CPAP) can restore functional residual capacity (FRC) to pre-operative value, ${ }^{6}$ Improve oxygenation ${ }^{7}$ and decrease work of breathing. ${ }^{8}$ Although CPAP is better than IS and IPPB, but its effects are not sustained. ${ }^{9}$ Bilevel positive airway pressure (BiPAP) is another non-invasive mode which has been used to treat many diseases like acute exacerbation of chronic bronchitis (AECB), ${ }^{10}$ obstructive sleep apnea $(\mathrm{OSA})^{11}$ and cardiogenic pulmonary oedema. ${ }^{12}$ Pressure support ventilation (PSV) in BiPAP allows recruitment of zones of alveolar collapse and PEEP prevents alveolar collapse at end expiration thereby improving oxygenation and decreasing postoperative atelectasis. Patient with low left ventricular ejection function (LVEF) tend to go into pulmonary congestion and edema once the positive pressure ventilation is weaned off in post CABG period. We hypothesized that post-extubation application of BIPAP may reduce the incidence of atelectasis and improve oxygenation indices in these groups of patients. Hence, we performed a randomized prospective, placebocontrolled study to see the effectiveness of prophylactic use of BIPAP in prevention of postoperative atelectasis in post cardiac surgical patients. 


\section{Methods}

Present study was conducted at tertiary care cardiac facility and included forty consecutive patients undergoing elective off pump coronary artery bypass graft surgery (OPCAB) with low LVEF $£ 35 \%$ (measured by ECHO) after approval of institutional ethics committee and written informed consent from all patients.. Baseline demographic profile (age, sex, weight) and smoking history and history of pulmonary disease were recorded for all patients.

Patients were randomized into 2 groups:

\section{i. Group B - BiPAP $(n=20)$}

\section{ii. Group C (Control) - Non BiPAP $(\mathrm{n}=20)$}

A comprehensive preoperative work up of all patients, once they had been optimized on medication was done in the form of baseline hemodynamic parameter, arterial blood gases (ABG), Chest x-ray (CXR)-PA view and corresponding lateral view (if required), liver function Test (LFT), renal function test (RFT) and complete blood count (CBC). Surgical and anesthetic techniques were same for both groups. Extubation was performed when the patient met the standard criteria for the same Patients assigned into group-B were started on BiPAP immediately following extubation for a period of 12 hours. On the other hand, group $\mathrm{C}$ patients were administered oxygen by venturi mask $\left(\mathrm{FiO}_{2}=0.6\right)$. Both groups received conventional (routine) chest physiotherapy. Post operatively the patient's temperature, arterial blood gases $(\mathrm{ABG})$, hemodynamic parameters [e.g. heart rate (HR), blood pressure (BP), cardiac output (CO), cardiac index (CI), systemic vascular resistance (SVR), pulmonary vascular resistance (PVR), pulmonary artery pressure (PAP], respiratory parameters [e.g. respiratory rate $(\mathrm{RR})$ and arterial saturation of hemoglobin $\left(\mathrm{SpO}_{2}\right)$ were recorded at baseline (0hours) and every 4 hourly. CXR, CBC and RFT were done every 24-hour. A radiologist who was blinded to the groups reported CXR. Radiological atelectasis score was defined according to Richter et al. ${ }^{13}$ 0- Clear lung field, 1-Plate atelectasis or slight infiltration, 2-Partial atelectasis, 3-Lobar atelectasis and 4-Bilateral lobar atelectasis. We also noted in-hospital mortality, ICU stay, total hospital stay, development of atelectasis and pneumonia during hospital stay.

Pneumonia was defined, if any three of the following criteria were present

i. New and persistent radiological infiltrate consistent with pneumonia

ii. Fever $>38^{\circ} \mathrm{C}$.

iii. Leukocytosis $>11000 / \mathrm{ml}$ or $<4000 / \mathrm{ml}$

iv. Purulent sputum

v. Microorganism isolated from at least one of the following samples

a. Broncho alveolar lavage (BAL)

b. End tracheal tube aspirate

c. Sputum

Patients in both groups had the same regimen of chest physiotherapy and IS. Postoperatively pain relief was managed by intravenous Tramadol hydrocholoride $50-100 \mathrm{mg}$ thrice daily and prn (maximum dose of $300 \mathrm{mg} /$ day) to remove bias of different modes of pain relief. All patients were kept on prophylactic antibiotic (injection Cefazoline 1g intravenous. preoperatively and thereafter every 8hourly till the chest tube removal) as per hospital protocol. Patients in both groups were also continued on ionotropic support, diuretic, vasodilators, anticoagulants, anti adrenergic etc as required. Any respiratory co morbidity e.g. chronic obstructive pulmonary disease (COPD), pneumonia etc. were also noted. The requirements of additional antibiotics in the postoperative period for respiratory or other infections in addition to the antibiotic given routinely were noted, as was reintubation/ tracheotomy.

\section{BiPAP Protocol}

All patients were thoroughly evaluated by a pulmonary physician preoperatively, who was unaware about treatment protocol in both groups. BiPAP machine, (Respironics Inc, Murrysville PA) is a pressure-limited ventilator, that cycles between adjustable inspiratory and expiratory pressure using either flow triggered or time triggered cycling modes. BiPAP was applied in all patients with a backup respiratory rate of 12-14 breath per minute with an initial IPAP setting of $8 \mathrm{~cm} \mathrm{H}_{2} \mathrm{O}$ and initial EPAP setting of $4 \mathrm{~cm} \mathrm{H}_{2} \mathrm{O}$ to maintain positive pressure gradient of $4 \mathrm{~cm} \mathrm{H}_{2} \mathrm{O}$ between inspiratory and expiratory phase. Supplemental $\mathrm{O}_{2}(8-101 / \mathrm{min})$ via the BiPAP machine was given in order to maintain the $\mathrm{SaO}_{2}$ above $94 \%$. A soft cushioned nasal or facemask (depending on patient's comfort) was used to provide BiPAP. Chinstrap was also used to avoid mouth leak in case of nasal mask or if the patient was a mouth breather. Patients with distension of the stomach had an or gastric tube placed to decompress the stomach. Nasal mask were switched to or nasal mask if there was significant air leakage through the mouth despite chinstrap or if the patient was not able to tolerate nasal mask.

Monitoring of clinical and hemodynamic parameters along with patient's comfort were done and if, the patient required more inspiratory assistance, pressure was increased by $2 \mathrm{~cm} \mathrm{H}_{2} \mathrm{O}$ increments every 3-5min until $\mathrm{SpO}_{2}(>94 \%)$ andPaO $(>60 \mathrm{mmHg})$ were optimized. On the other hand if patient felt that the pressure was too high, the aspiratory pressure was lowered in $2 \mathrm{CmH}_{2} \mathrm{O}$ decrements every $3-5$ min until comfort was obtained. Similarly for hypoxemic patients, EPAP was raised in increments of $2 \mathrm{CmH}_{2} \mathrm{O}$ with IPAP at fixed interval above EPAP (i.e. PS was maintained at $4-5 \mathrm{CmH}_{2} \mathrm{O}$ ). For hypersonic patients IPAP was raised in increments of $2 \mathrm{CmH}_{2} \mathrm{O}$ with EPAP raised in a ratio to IPAP of approximately 1:2.5. After every ventilator setting change, $\mathrm{ABG}$ was done to monitor the blood gases. Successful BIPAP management was defined as

i. Increased $\mathrm{PaO}_{2}$, increased $\mathrm{SpO}_{2}$ or decreased $\mathrm{PaCO}_{2}$

ii. Improvement in pulse and respiratory rate and avoidance of endotracheal reintubation (ET)

\section{Statistical Analysis}

The Chi-square or Fisher exact tests were applied for comparison of categorical data as appropriate. Results were expressed as mean $\pm \mathrm{SD}$. Mean value of group B and C were compared by using student t-test. A p-value of less than 0.05 was considered significant. All analysis were done by using SPSS statistical software (version 10.0; SPSS Inc. Chicago, IL).

\section{Results}

There was no significant difference in demographic profile (age, gender, weight, height and smoking status (pack year), co morbid 
conditions and pulmonary function test between two groups (Table $1)$. Duration of surgery $(248 \pm 19 \mathrm{~min} v / \mathrm{s} 252 \pm 17 \mathrm{~min}, \mathrm{p}=0.488)$ and postoperative total ventilator time $(482 \pm 18 \mathrm{~min} \mathrm{v} / \mathrm{s} 491 \pm 23 \mathrm{~min}$, $\mathrm{p}=0.177$ ) were statistically similar in both groups. The absolute values or proportional changes in vitals as compared to baseline e.g. HR, RR, systolic blood pressure (SP), and diastolic blood pressure (DP) were not significantly different in both groups. Table $2 \mathrm{pH}$ values were similar in both groups but $\mathrm{PaO}_{2}$ was higher and $\mathrm{PaCO}_{2}$ was lower throughout study period in group $\mathrm{B}$. $\mathrm{CO}$ and $\mathrm{CI}$ were reduced in group B after application of BiPAP (at 0hrs - 4.2 \pm 0.7 ) and (at $12 \mathrm{hrs}-4.3 \pm 0.4)(\mathrm{p}<0.05)$ which was statistically significant (Table 3$)$. All vital parameters were recorded for both groups every 4 hourly, however for calculations, data only at $0 \mathrm{hr}, 1 \mathrm{hr}, 24 \mathrm{hr}$ and $48 \mathrm{hr}$ are taken as shown in Tables 2, Table 3. There was significantly reduced incidence of atelectasis in group B as compared to group C $(10 \% \mathrm{v} / \mathrm{s}$ $60 \%)(\mathrm{p}<0.003)$ while the incidence of pneumonia was twice in group $\mathrm{C}(\mathrm{n}=1 \mathrm{v} / \mathrm{s} \mathrm{n}=2)$ (Table 4$)$.

Table I Baseline characteristics of patients in both group

\begin{tabular}{|c|c|c|c|}
\hline & Group B $(n=20)$ & Group C $(n=20)$ & p Value \\
\hline Age (yrs) (Mean $\pm S D)$ & $54.9 \pm 6.34$ & $56.1 \pm 8.08$ & 0.605 \\
\hline $\operatorname{Sex}(M / F)$ & $18 / 2$ & $18 / 2$ & I \\
\hline Weight (kg) & $78 \pm 4$ & $76 \pm 6$ & 0.223 \\
\hline Smokers (n) & 8 & 6 & 0.74 \\
\hline \multicolumn{4}{|l|}{ History } \\
\hline Hypertension (n) & 9 & 7 & 0.747 \\
\hline Diabetic Mellitus (n) & 4 & 6 & 0.715 \\
\hline COPD/Asthma (n)\% & (4) 20 & (5) 25 & 1 \\
\hline Previous MI / CAD (n) & 20 & 20 & 1 \\
\hline \multicolumn{4}{|c|}{ Preoperative PFT(Mean \pm SD) } \\
\hline $\mathrm{FVC}(\mathrm{ml})$ & $3398 \pm 736$ & $3295 \pm 627$ & 0.637 \\
\hline FEVI (ml) & $2580 \pm 678$ & $2523 \pm 714$ & 0.798 \\
\hline
\end{tabular}

COPD, chronic obstructive pulmonary disease; FVC, forced vital capacity; $\mathrm{FEV}_{1}$, forced expiratory volume in I second

Table 2 Vital and physiological parameters recorded in both groups

\begin{tabular}{|c|c|c|c|c|c|c|c|c|c|c|}
\hline & \multicolumn{2}{|c|}{ Preoperative } & \multicolumn{2}{|l|}{ Ohr } & \multicolumn{2}{|l|}{$12 \mathrm{hr}$} & \multicolumn{2}{|l|}{$24 \mathrm{hr}$} & \multicolumn{2}{|l|}{$48 \mathrm{hr}$} \\
\hline & Gr. B & Gr. C & Gr. B & Gr. C & Gr. B & Gr. C & Gr. B & Gr. C & Gr. B & Gr. C \\
\hline Heart Rat/min & $98 \pm 16$ & $100 \pm 14$ & $92 \pm 16$ & $96 \pm 12$ & $93 \pm 14$ & $98 \pm 14$ & $93 \pm 13$ & $93 \pm 13$ & $90 \pm 11$ & $98 \pm 13$ \\
\hline $\mathrm{BP}(\mathrm{SP}) \mathrm{mmHg}$ & $115 \pm 11$ & $122 \pm 14$ & $119 \pm 18$ & $118 \pm 10$ & $118 \pm 9$ & $120 \pm 13$ & $114 \pm 8$ & $116 \pm 10$ & $|24 \pm| \mid$ & $114 \pm 10$ \\
\hline $\mathrm{BP}(\mathrm{DP}) \mathrm{mmHg}$ & $57 \pm 6$ & $66 \pm 10$ & $60 \pm 8$ & $60 \pm 7$ & $61 \pm 6$ & $60 \pm 6$ & $57 \pm 8$ & $62 \pm 8$ & $54 \pm 4$ & $55 \pm 12$ \\
\hline $\mathrm{PAP}(\mathrm{SP}) \mathrm{mmHg}$ & $35 \pm 10$ & $32 \pm 7$ & $32 \pm 9$ & $27 \pm 6$ & $36 \pm 8$ & $31 \pm 6$ & $34 \pm 6$ & $33 \pm 7$ & $40 \pm 12$ & $24 \pm$ \\
\hline PAP (DP) $\mathrm{mmHg}$ & $15 \pm 7$ & $15 \pm 3$ & $14 \pm 5$ & $11 \pm 4$ & $14 \pm 4$ & $14 \pm 3$ & $2 \pm 3$ & $12 \pm 4$ & $17 \pm 4$ & $99 \pm 1$ \\
\hline $\mathrm{CO}(\mathrm{L} / \mathrm{mi})$ & $4.4 \pm 0.8$ & $4.7 \pm 0.9$ & $4.2 \pm 0.7^{*}$ & $4.7 \pm 0.7$ & $4.3 \pm 0.4 *$ & $4.8 \pm 0.6$ & $4.2 \pm 0.4$ & $4.5 \pm 0.6$ & $4.2 \pm 0.3$ & $4.5 \pm 0.4$ \\
\hline $\mathrm{Cl}(\mathrm{L} / \mathrm{mm})$ & $2.6 \pm 0.5$ & $2.7 \pm 0.4$ & $2.4 \pm 0.4$ & $2.7 \pm 0.3$ & $2.4 \pm 0.3$ & $2.7 \pm 0.3$ & $2.5 \pm 0.3$ & $2.7 \pm 0.4$ & $2.5 \pm 0.1$ & $2.7 \pm 0.4$ \\
\hline SVR dyne sec cm-5 & $134 \pm 365$ & $1243 \pm 283$ & $1379 \pm 839$ & $1233 \pm 177$ & $1282 \pm \mid 48$ & $1235 \pm 182$ & $1280 \pm 112$ & $1250 \pm 167$ & $1354 \pm \mid 44$ & $1266 \pm 137$ \\
\hline PVR dyne sec $\mathrm{cm}-5$ & $|5| \pm 82$ & $154 \pm 67$ & $173 \pm 98$ & $120 \pm 45$ & $172 \pm 46 *$ & $|3| \pm 5 \mid$ & $173 \pm 73$ & $152 \pm 35$ & $12 \mid \pm 72$ & $91 \pm 42$ \\
\hline
\end{tabular}

BP, blood pressure; SP, systolic pressure; DP, diastolic pressure; PAP, pulmonary artery pressure; SVR, systemic vascular resistance; PVR, pulmonary vascular resistance; *: Significant; $\mathrm{P}<0.05$. 
Table 3 Vital and physiological parameters recorded in both groups-respiratory

\begin{tabular}{|c|c|c|c|c|c|c|c|c|c|c|}
\hline & Preopera & ative & $0 \mathrm{hr}$ & & $12 \mathrm{hr}$ & & $24 \mathrm{hr}$ & & $48 \mathrm{hr}$ & \\
\hline & Gr. B & Gr. C & Gr. B & Gr. C & Gr. B & Gr. C & Gr. B & Gr. C & Gr. B & Gr. C \\
\hline Respiratory rate/ min & $19 \pm 3$ & $18 \pm 3$ & $18 \pm 3$ & $19 \pm 2$ & $19 \pm 3$ & $19 \pm 2$ & $19 \pm 3$ & $19 \pm 2$ & $19 \pm 1$ & $18 \pm 1$ \\
\hline \multicolumn{11}{|l|}{ ABG } \\
\hline PH & $7.4 \pm .05$ & $7.5 \pm .04$ & $7.4 \pm .09$ & $7.4 \pm .03$ & $7.4 \pm .04$ & $7.4 \pm .04$ & $7.4 \pm .04$ & $7.4 \pm .04$ & $7.4 \pm .05$ & $7.4 \pm .001$ \\
\hline $\mathrm{PaO}_{2} \mathrm{mmHg}$ & $156.4 \pm 55$ & $148 \pm 40$ & $|50 \pm 4|$ & $|40 \pm 4|$ & $146 \pm 37^{*}$ & $121 \pm 18$ & $151 \pm 39$ & $12 \pm 12$ & $|46 \pm 4|$ & $110 \pm 9 *$ \\
\hline $\mathrm{PaCO}_{2} \mathrm{mmHg}$ & $38.5 \pm 4.6$ & $39.5 \pm 5.5$ & $39.5 \pm 3.9$ & $40 \pm 3.2$ & $40 \pm 5$ & $40 \pm 5$ & $40 \pm 4$ & $42 \pm 2.7$ & $40 \pm 4$ & $42 \pm 2$ \\
\hline $\mathrm{SpO}_{2}(\%)$ & $99 \pm 1.4$ & $98 \pm 12$ & $99.2 \pm 1.1$ & $98 \pm 6.6$ & $99.4 \pm 3.6$ & $97.7 \pm 7$ & $99 \pm 1.7$ & $99 \pm 1$ & $99.6 \pm .5$ & $100 \pm .0$ \\
\hline \multicolumn{11}{|l|}{ Pulmonary Artery ABG } \\
\hline $\mathrm{PaO}_{2} \mathrm{mmHg}$ & $36 \pm 7$ & $33 \pm 3$ & $33 \pm 2$ & $34 \pm 3$ & $34 \pm 6$ & $33 \pm 4$ & $33 \pm 2$ & 333 & $28 \pm 3$ & $34 \pm 2$ \\
\hline $\mathrm{PaCO}_{2} \mathrm{mmg}$ & $43 \pm 6$ & $44 \pm 6$ & $45 \pm 4$ & $45 \pm 3$ & $45 \pm 4$ & $46 \pm 3$ & $45 \pm 3$ & 484 & $47 \pm 4$ & $44 \pm 5$ \\
\hline $\mathrm{SvO}_{2}(\%)$ & $68 \pm 9$ & $64 \pm 6$ & $67 \pm 7$ & $67 \pm 6$ & $65 \pm 7$ & $66 \pm 9$ & $68 \pm 5$ & 667 & $55 \pm 14$ & $68 \pm 5$ \\
\hline
\end{tabular}

$\mathrm{SpO}_{2}$, arterial oxygen saturation; $\mathrm{Pa} \mathrm{O}_{2}$, partial pressure of oxygen; $\mathrm{PaCO}$, partial pressure of $\mathrm{CO}_{2}, \mathrm{CO}$, cardiac output; $\mathrm{Cl}$, cardiac index; $\mathrm{SvO}$, mixed venous oxygen saturation; *: Significant, $\mathrm{P}<0.05$.

Table 4 Outcome measures in both groups

\begin{tabular}{llll}
\hline & Group B & Group C & p-value \\
\hline Basal Atelectasis (\%) & 0.1 & 0.6 & 0.003 \\
& $(2 / 20)$ & $(I 2 / 20)$ & \\
Pneumonia (\%) & 0.05 & 0.1 & $\mathrm{I}$ \\
ICU Stay (days) & $(\mathrm{I} / 20)$ & $(2 / 20)$ & \\
Hospital Stay (days) & $3.6 \pm 1.2$ & $4.3 \pm 1.5$ & 0.085 \\
& $8.9 \pm 3.7$ & $9.5 \pm 3.1$ & 0.582 \\
Mortality (\%) & 0.05 & 0 & 0.047 \\
& $(\mathrm{I} / 20)$ & & \\
\hline
\end{tabular}

\section{Discussion}

Postoperative pulmonary restriction syndrome i.e. occurrence of basal atelectasis with decline in lung function leading to various complications is a well-known entity after cardio thoracic or upper abdominal surgery. This restriction of pulmonary function usually persists from a few days to 2-3weeks leading to postoperative pulmonary complications and increasing the morbidity and cost of treatment. This alteration of ventilatory function is multi factorial: phrenic nerve dysfunction/palsy, effect of anesthetic/analgesic drugs, pain, mechanical functional alteration of chest wall due to sternotomy, pleural opening, prolonged recumbent position. ${ }^{14,15}$ diaphragmatic dysfunction, associated cardiac surgery and underlying lung status. All these combined together contribute to major cause of post operative morbidity and mortality .During normal breathing, large intermittent breaths (about three time the tidal volume), which are known as sigh, occur about 10 times per hour. Post operatively such sighing is absent and the shallow rapid respiration may decrease ventilation to the dependent lung region and may contribute to the 
development of atelectasis with its associated complications. ${ }^{16}$ To avoid post operative pain because of expansion of rib cage along with low compliance of lung and chest wall and hence, increased elastic work of breathing. ${ }^{17}$ Patient tries to compensate by taking shallow rapid breaths which further decreases lung volume. ${ }^{18}$ To avoid these post operative pulmonary complications many therapeutic and prophylactic maneuvers and devices have been used in past with varying results. Out of these devices IS has gained popularity and currently is a common mode of delivering post operative respiratory therapy along with conventional physiotherapy (i.e. coughing, deep breathing, postural drainage). The theory behind IS, is that it facilitates patient to take maximal deep inspiration to maximally inflate their lung and to sustain that inflation with resultant opening of previously collapsed alveoli. Maximal lung inflation increases Trans pulmonary pressure during inspiration. If the re-expanded alveoli remain inflated during expiration, FRC increases. However, IS therapy is entirely patient's effort dependent and requires close cooperation between patient and respiratory therapist. Non Invasive Positive Pressure Ventilation (NIPPV) has become increasingly common mode of ventilation in different pulmonary and extra pulmonary disease e.g. OSA, chronic hypersonic respiratory failure in COPD, neuromuscular disease etc. BiPAP, a combination of pressure support ventilation and PEEP, is a barometric ventilatory mode, the action of which is determined by the difference between IPAP and EPAP. A pressure controlling valve maintains pressure at two preset level i.e IPAP and EPAP. In the spontaneous mode, the unit switches from IPAP to EPAP when the patients inspiratory flow reaches $20 \mathrm{ml} / \mathrm{sec}$. The IPAP level is maintained for at least $180 \mathrm{~ms}$, the ventilator cycles to EPAP, when patients inspiratory flow decreases below a threshold level. If an expiratory effort is detected or if aspiratory period is held for $>3$ seconds, the device automatically switches from IPAP to EPAP. The BIPAP system differs from airway pressure release ventilator, which has two level of EPAP applied for set period of time and allows spontaneous breathing to occur. Owing to a decelerating inspiratory waveform, PSV allows recruitment of zones of alveolar collapse and results in more homogenous distribution of ventilation. ${ }^{19-21}$ PSV further reduces the work of breathing. ${ }^{22}$ PEEP applied through BIPAP prevents expiratory collapse of alveoli hence increasing FRC and mean airway pressure. Therefore BIPAP could improve postoperative pulmonary function and prevent the development of atelectasis. Delivery of PSV by BIPAP can be spontaneous, spontaneous/Time ( $\mathrm{S} / \mathrm{T}$ ) or Timed mode. The $\mathrm{S} / \mathrm{T}$ mode combines the two triggering modes, and functions like the assist/control mode on a standard volume ventilator. In our study we used $\mathrm{S} / \mathrm{T}$ mode of BIPAP with a backup rate of 12-14 breaths per minute. BiPAP system is applied through a comfortable nasal or or nasal mask, this system compensates for stable leaks through the mouth and around the nasal mask thus maintaining the pressures at present levels. In our study, the absolute values or proportional changes from baseline in vital parameters of patients like HR, RR, systolic, diastolic and mean arterial BP and pulmonary artery systolic and diastolic pressures did not differ significantly in both groups. These findings are in accordance with those of Joseph et al. ${ }^{23}$ However they did not study pulmonary artery pressures. However in relation to baseline values BP, HR, RR did not show significant change in either group (Table 2). Mean pulmonary artery systolic (PASP) and diastolic pressure (PADP) was similar in both groups, however group $\mathrm{C}$ showed a lower PASP and PADP at $48 \mathrm{hrs}$ but the difference was not significant. This could be attributable to direct transmission of airway pressure in group $\mathrm{B}$ to the intra thoracic structures i.e pulmonary artery. Regarding the $\mathrm{ABG}, \mathrm{pH}$ was similar in both groups but the $\mathrm{PaO}_{2}$ values were higher throughout the study time in group $\mathrm{B}$ as compared to group $\mathrm{C}$, and the difference was significant at 12 hours. At 48 hours the $\mathrm{PaO}_{2}$ value of group $\mathrm{B}$ was significantly higher $(\mathrm{p}<.003)$, than group $\mathrm{C}$ (Table 3 ). Although the $\mathrm{PaCO}_{2}$ values were slightly higher in group $\mathrm{C}$, but the difference was not significant. $\mathrm{SpO}_{2}$ was higher in group $\mathrm{B}$ throughout 48 hours at all points in time, but the difference was not significant (Figure 1). As far as the pulmonary artery ABG was concerned it had no significant differences in pulmonary artery $\mathrm{PaO}_{2}$ and pulmonary artery $\mathrm{PaCO}_{2}$ level in both groups. No other study had included pulmonary artery $\mathrm{ABG}$ in their study. Our ABG, $\mathrm{PaCO}_{2}$ findings are in conformity with Joseph et al, who also did not find any difference in both the groups. As Table 2 shows, both the CO and CI were lower in group B right from pre operative period to the termination of study. This may be attributable to baseline difference in the $\mathrm{CO}$ and $\mathrm{CI}$ in both study population but after application of BIPAP the difference in $\mathrm{CO}$ and $\mathrm{CI}$ between both groups were more as compared to pre operative level. This may be because of impairment of venous return. Since all our patients had low LVEF ( $£ 35 \%$ ) and after application of BiPAP there may have been certain impedance to venous return due to increased intra thoracic pressure thus contributing to the decrease in $\mathrm{CO}$ and $\mathrm{CI}$ (Figure 2). Philip et al. ${ }^{24}$ also found decrease in $\mathrm{CO}$ and $\mathrm{CI}$ in patient of cardiac failure and low pulmomary capillary wedge pressure (PCWP) after application of CPAP or BiPAP but, in cases of acute cardiogenic pulmonary edema with high PCWP the positive intra thoracic pressure has been reported to increase stroke volume index and to decrease intrapulmonary shunt and left ventricular after load without compromising CI. Lin et al. ${ }^{25,26}$ found that at $30 \mathrm{~min}$ BIPAP group had greater reduction in systolic BP $(\mathrm{p}<.005)$, and mean arterial pressure (p-.03) than the CPAP group. Mehta $\mathrm{S}$ et al found that myocardial infarction (MI) rate was higher in the BIPAP group (71\%) compared with the CPAP group (31\%) and historically matched controls (38\%) (p.05) ${ }^{26}$ We did not find that, may be because all our patients in both groups were post CABG with past history of MI, also the number of study subjects were small.

The most significant finding of our study was that there was significantly reduced incidence of pulmonary atelectasis in group B $(10 \%$ vs $60 \%)(p<0.003)$ (Table 4). Study done by Jean et al was not designed to show any benefit of decreasing the postoperative pulmonary restriction syndrome with BiPAP on the incidence of postoperative pulmonary complications. ${ }^{27}$ Therefore they did not perform postoperative chest X-Ray to diagnose atelectasis or other complications. Our findings are in conformity to that of Matte et al. They also found low incidence of atelectasis (15\% vs $30 \%)$ in CPAP or BiPAP and IS group. ${ }^{28}$ Christine Stock et al. ${ }^{29}$ studied the role of CPAP, IS and coughing /deep breathing (CDB) to see the comparative efficacy of these manoeuvers on recovery of pulmonary functions post operatively. They found roentogenographic evidence of atelectasis 72 hours post operatively in 23\% (CPAP group), $42 \%$ (CDB group) and $41 \%$ (IS group) of study subjects. ${ }^{29}$

Their findings were also consistent with our findings (Figure 3). Regarding the severity of atelectasis patients in group B had quantitatively and qualitatively less incidence of atelectasis on first two post operative days. In group B both patients, who developed atelectasis, the atelectasis score was $£ 2$, while in group $\mathrm{C}, 8$ patients had atelectasis score of $£ 2$ (p 0.067), three patients had score of $£ 3$ (p $0.231)$ and 1 patient developed bilateral lobar atelectasis (score $=4) .13$ (p 0.106, (Table 5). 


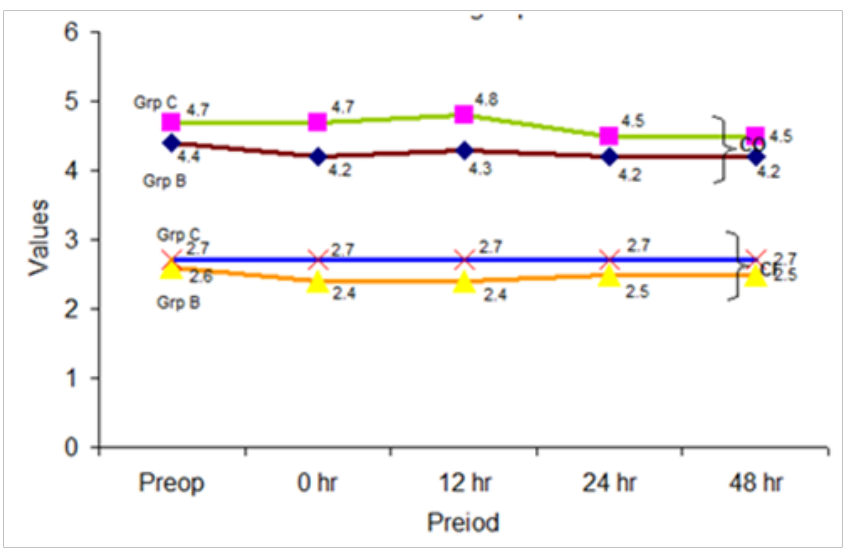

Figure I Graph II Vital \& Physiological Parameters (hemodynamics) in both groups.

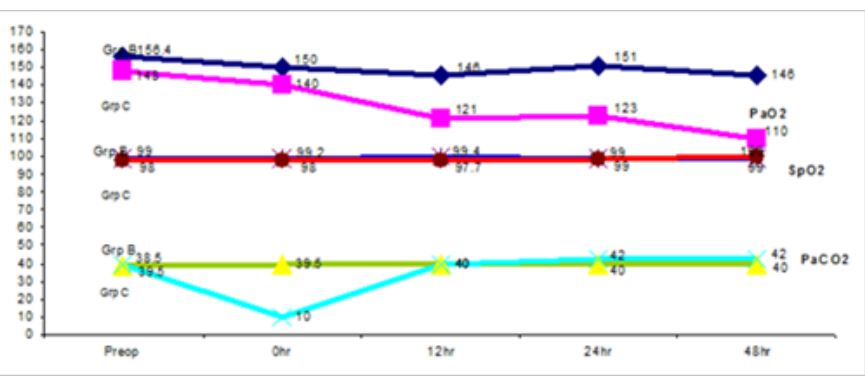

Figure 2 Showing Respiratory Parameters among Two Groups.

Pasquina et al. ${ }^{30}$ in a comparative study of CPAP and non invasive pressure support ventilation (NI PSV) to treat atelectasis after cardiac surgery observed an improvement in the radiological atelectasis score in $60 \%$ of the patients with NIPSV versus $40 \%$ of those receiving $\mathrm{CPAP}(\mathrm{p}=0.02)$. They did not find any difference in oxygenation $\left(\mathrm{PaO}_{2} /\right.$ $\mathrm{FiO}_{2}$ ), pulmonary function tests or length of stay. ${ }^{30}$ Although their findings are similar to ours, but they analyzed the therapeutic effects of NIPSV on atelectasis after cardiac surgery while we observed the prophylactic effect of BiPAP for the development of atelectasis after cardiac surgery. As already stated BiPAP increases the FRC and keeps the alveoli open throughout both phases of respiration. There are fewer tendencies for segment or any part of segment to collapse because of alveolar interdependence, which helps to prevent an alveolus to collapse spontaneously. This tendency, which is enhanced by EPAP, tends to stabilize the alveoli because the alveolar pressure is kept above atmospheric pressure during expiration (PEEP) so the alveoli hold the adjacent alveoli open and not let them collapse. Although the development of pneumonia was twice in group $\mathrm{C}$ but this was statistically insignificant because of small study size and this may be a chance finding. Only one and two patients in group B and group $\mathrm{C}$ respectively developed pneumonia, which could not be explained solely on the basis of BiPAP. There were other confounding factors too, which may lead to bias. Mean duration of ICU stay and hospital stay was $3.6 \pm 1.2$ days and $8.9 \pm 3.7$ days in group B, while it was $4.3 \pm 1.5$ days and $9.5 \pm 3$. 1 days in group $C$, but it was non-significant $(p$ 0.085 and 0.582 respectively). Our findings are consistent with Jean et al. There was one death in group B due to intractable arrhythmias and none in group C. Jean et al found significant improvement in FVC, FEV, PEFR in BIPAP group (12/4) and Stock et al and Lindner et al also found improvement in FRC and FEV1 and FVC value after CPAP therapy, but in our study, we did not perform post operative
PFT. In spite of use of internal mammary artery in all patients for surgical myocardial revascularization, the post operative pulmonary atelectasis was significantly lower in our BiPAP group, while, in contrast P. matte, Ferdinand et al. ${ }^{31}$ found a large impairment in post operative pulmonary function when the mammary arteries were used as conduit for revascularization as compared to the saphenous vein graft.

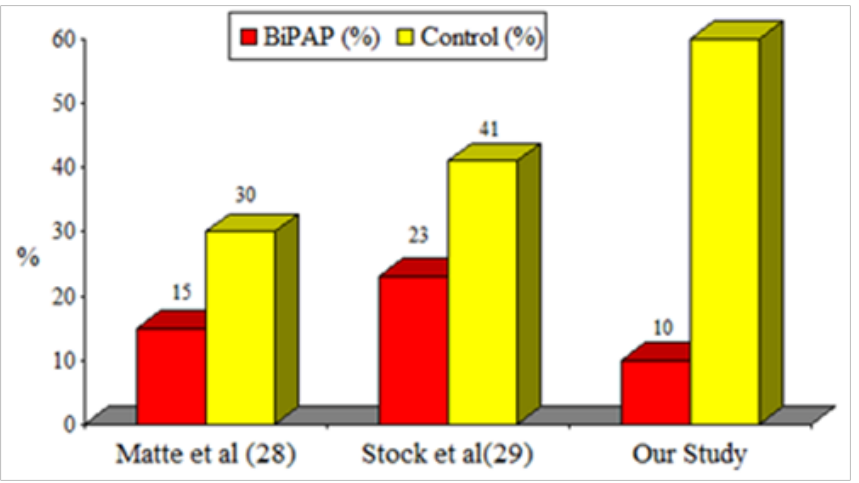

Figure 3 Comparison of incidence of atelectasis in different studies.

Table 5 Radiographic Atelectasis Score* In Both Groups according to Richter et al. ${ }^{13}$

\begin{tabular}{llll}
\hline & Group B & Group C & P value \\
\hline & $£ 2(n=2)$ & $£ 2(n=8)$ & 0.067 \\
Radiographic Atelectasis Score & - & $€ 3(n=3)$ & 0.231 \\
& - & $4(n=1)$ & 0.106 \\
\hline
\end{tabular}

*Radiological Atelectasis Score (Richter et al. ${ }^{13}$ ); Clear Lung Field I: Plate atelectasis or Slight Infiltration; 2:Partial Atelectasis; 3:Lobar Atelectasis and; 4: Bilateral Lobar Atelectasis

\section{Conclusion}

In summary for a majority of patients undergoing cardiac surgery with poor LVEF $<35 \%$ use of BIPAP along with conventional physiotherapy can be considered as an effective means of avoiding the deleterious consequences of cardiac surgery on post operative pulmonary complications originating from atelectasis like ventilator associated pneumonia. This was demonstrated by significantly lower $(10 \%$ vs $60 \%)$ incidence of atelectasis, lower incidence of pneumonia and higher $\mathrm{PaO}_{2}$. Large multicentre study is required to show other beneficial effects of BiPAP on other variables like ICU/hospital stay and morbidity or mortality.

\section{Limitations}

As this study was a small size case controlled, non blinded study (i.e. the respiratory therapist was not blinded in order to make ventilator adjustments) and the follow up of patients was short and post operative PFT were not performed so the improvement in FEV, FVC could not be compared to test the functional improvement after BiPAP. We also expected to find an effect on the development of pneumonia, ICU stay, total hospital stay, mortality but because the study was small with short follow up that difference in these variables could not be studied. 


\section{Acknowledgements}

None.

\section{Conflict of interest}

The author declares no conflict of interest.

\section{References}

1. Ford GT, Rosenal TW, Clergue F, et al. Respiratory physiology in upper abdominal surgery. Clin Chest Med. 1993;14(2):237-252.

2. Clergue F, Pensard JL. Respiratory changes induced by upper abdominal and cardiac surgery. In: Vincent JL editor. Update in intensive care and emergency medicine. Europe: Springer; 1990. p. 166-173.

3. Hedensteirna G. Mechanism of postoperative pulmonary dysfunction. Acta Chir Scand. 1989;550:152-158.

4. Oikkonen M, Karjalainen K, Kähärä V, et al. Comparison of incentive spirometry \& intermittent positive pressure breathing after coronary artery bypass grafting. Chest. 1991;99(1):60-65

5. Celli BR. Perioperative respiratory care of the patients undergoing upper abdominal surgery. Clin Chest Med. 1993;1492:253-261.

6. Linder KH, Lotz P, Ahnefeld FW. Continuous positive airway pressureeffect on functional residula capacity, vital capacity and its subdivisions. Chest. 1987;92(1):62-70.

7. Pinilla JC, Oleniuk FH, Tan L, et al. Use of nasal continuous positive airway pressure mask in the treatment of postoperative atelectasis in aorto coronary bypass surgery. Crit Care Med. 1990;18(8):836-840.

8. Martin JG, Shore S, Engel LA. Effect of continuous positive airway pressure on respiratory mechanics and pattern of breathing in induced asthma. American Review of Respiratory Disease. 1982;126(5):812817.

9. Ricksten SE, Bengtsson A, Soderberg C, et al. Effect of periodic positive airway pressure by mask on postoperative pulmonary function. Chest. 1986;89(6):774-781.

10. S Nava, N Ambrosino, F Rubini, et al. Effect of nasal pressure support ventilation and expiratory PEEP on diaphragmatic activity in patients with severe stable COPD. Chest. 1993;103(1):143-150.

11. Waldhorn RE. Nocturnal nasal intermittent positive pressure ventilation with BiPAP in respiratory failure. Chest. 1992;101(2):516-521.

12. Pennock BE, Kaplan PD, Carlin BW, et al. Pressure support ventilation with a simplified ventilatory support system administered with a nasal mask in patients with respiratory failure. Chest. 1991;100(5):13711376 .

13. Richter Larsen K, Ingwersen U, Thode S, et al. Mask physiotherapy in patients after heart surgery: A controlled study. Intensive Care Medicine. 1995;21(6):469-474.

14. McMichael J, McGibbon JP. Postural changes in the lung volume. Clin Sci Molec Med. 1939;4:176-183.

15. Whitfield AGW, Waterhouse JAH, Arnott WM. The total lung volume and its sub-division: A study in physiological norms. II. The effect of posture. Br J Soc Med. 1950;4(2):86-97.
16. Zikria BA, Spencer JL, Kinney BM. Alteration in ventilatory functions and breathing patterns following surgical trauma. Ann Surg. 1974;179(1):1-7.

17. Downs JB, Modell JH. Patterns of respiratory support aimed at pathophysiological conditions. In: ASA refresher course in Anesthesioilogy. USA: Lipincotts Co; 1997.

18. Weled BJ, Winfrey D, Downs JB. Measuring exhaled volume with continuous positive airway pressure $\&$ intermittent mandatory ventilation. Chest. 1979;76(2):166-169.

19. Al Saddy, Bennet FD. Decelerating inspiratory flow waveform improves lung mechanics \&gas exchange in patients on Intermitent positive pressure ventilation. Intensive Care Medicine. 1985;11(2):68-75.

20. Chan K, Abraham E. Effects of inverse ratio ventilation on Cardiopulmonary parameters in severe respiratory failure. Chest. 1992;102(5):15561561.

21. Ravenscraft SA, Burke WC, Marini JJ. Volume cycled Decelerating flow: An alternative form of mechanical ventilation. Chest 1992;101(5):1342-1351.

22. Brochard L, Isabey D, Piquet J, et al. Reversal of exacerbation of C.O.P.D. by inspiratory assistance with a face mask. NEJM. 1990;323(22):15231530 .

23. Masip J, Betbesé AJ, Páez J, et al. Non invasive pressure support ventilation versus conventional oxygen therapy in acute cardiogenic pulmonary oedema. A randomised trial. Lancet. 2000;356(9248):2126-2132.

24. Philip Joët FF, Paganelli FF, Dutau HL, et al. Heamodynamic effects of Bilevel nasal pressure support ventilation in patient with heart failure. Respiration. 1999;66(2):136-143.

25. Lin M, Yang YF, Chiang HT, et al. Reappraisal of CPAP therapy in acute cardiogenic pulmonary oedema; short term results \&long term follow up. Chest. 1995;107(5):1379-1386.

26. Mehta S, Jay GD, Woolard RH, et al. Randomised prospective trial of BiPAP versus CPAP in acute pulmonary oedema. Critical care medicine. 1997;25(4):620-628.

27. Jean LJ, Thierry MS, Jean Daniel, et al. Effect of BiPAP mechanical ventilation on the postoperative pulmonary restriction syndrome in obese patient undergoing Gastroplasty. Chest. 1997;111(3):665-670.

28. Matte P, Jacquet L, Dyck V, et al. Effects of conventional physiotherapy, continuous positive airway pressure and non-invasive ventilatory support with bilevel positive airway pressure after coronary artery bypass grafting. Acta Anaesthesiol Scand. 2000;44(1):75-81.

29. Stock MC, Downs JB, Corkran ML. Pulmonary function before \& after CPAP by mask. Critical care medicine. 1984;12(11):973-974

30. Pasquina P, Merlani P, Granier JM, et al. Continuous positive airway pressure versus Non-Invasive pressure support ventilation to treat atelectasis after cardiac surgery. Anaesth Analg. 2004;99(4):1001-1008.

31. Ferdinande PG, Beets G, Micheles A. PFT after different technique for CABG surgery. Intensive care medicine. 1988;14:623-627. 